\title{
Extending Design Science Research Methodology for a Multicultural World
}

\author{
Carl Lawrence, Tuure Tuunanen, and Michael D. Myers \\ Information Systems and Operations Management, \\ University of Auckland, \\ Auckland 1142, New Zealand
}

\begin{abstract}
Design science research (DSR) is a relatively new approach in information systems research. A fundamental tenet of DSR is that understanding comes from creating information technology artifacts. However, with an increasingly connected and globalized world, designing IT artifacts for a multicultural world is a challenge. The purpose of this paper, therefore, is to propose extending the DSR methodology by integrating critical ethnography to the evaluation phase. Critical ethnography provides a way for IS researchers using DSR to better understand culture, and may help to ensure that IT artifacts are designed for a variety of cultural contexts.
\end{abstract}

Keywords: Design science research methodology, critical ethnography, mobile services, culture.

\section{Introduction}

Design science research (DSR) aims to improve our understanding of information systems phenomena by creating information technology artifacts. The artifacts created embody the solution for a problem previously defined (Hevner et al. 2004). In an increasingly connected and globalized world, however, IT artifacts are created for use in a variety of cultural contexts. The multicultural diversity of potential users and organizations suggests that information systems designers need a better understanding of culture and what it means for IS development (Kappos and Rivard 2008). We suggest that the task is much more complex than simply providing a product or service in a different language or creating a new format for a website. Complex social, cultural, political, and historical factors now come into play and potentially affect the way that information systems are perceived and adopted.

If creating effective IT artifacts is the goal, designing these artifacts to fit the needs of culturally diverse clients is what challenges us. We need to design better artifacts that truly enable people to work more effectively. We also want to find a method that uses local cultural traditions to their advantage, rather than impose alien, nonindigenous systems that will most likely end up being ineffective (Kumar et al. 1998; Ngwenyama and Lee 1997). Integrating valuable elements of culture into new innovations requires a culturally focused study prior to design in order to evaluate what is of value. 
At the moment the evaluation of IT artifacts is usually achieved by applying quantitative methods not informed by theory, and when theories have been applied, they have been primarily techno-centric in origin (Kumar et al. 1998). Traditional artifact evaluation also tends to favor a summative approach at an individual level and does not view the use of the artifact in social work spheres (Diaper and Lindgaard 2008). We suggest, however, that the evaluation phase of DSR can be modified in a way to tackle problems of cultural diversity (Klecun and Cornford 2005). Used formatively, we would be acknowledging a known issue-the potential mismatch between the design context and the use context-starting with trying to understand the culture that is the target of the artifact (Thimbleby et al. 2001). Of course, we should not underestimate the difficulty of designing information systems for multiple cultures. The problem is not just one of aesthetics (how the artifact appears), but may represent a deeper, underlying issue of what that technology represents and how it is (or is not) appropriated by people.

This paper, therefore, seeks to present arguments supporting the use of a critical ethnographic evaluation in a formative context. To do this, the paper builds on earlier work on ethnography in information systems (Harvey and Myers 1995; Myers 1999) and software design (Simonsen and Kensing 1997). The goal is to gain greater insight into culture before the design process even begins in order to understand, evaluate, and extract elements that the bring added value to the final artifact.

We begin by looking at some cultural challenges in IS research and how critical ethnography may be able to address these challenges. We look at DSR and the potential to integrate critical ethnography into DSR evaluation. We then attempt to apply that evaluation method to a recent study in design science. Finally, we present our findings and conclusions.

\section{The Cultural Challenge in Is Research}

Understanding culture represents both a challenge and an opportunity for information systems researchers (Kumar et al. 1998; Myers 1999), not least because there are many different definitions and conceptualizations of culture. Definitions range from the overly simplistic to complex. Many IS studies concerned with various cultural aspects have tended to rely on Hofstede's $(1980,1991)$ model of national culture. However, Hofstede's model has been described as rather simplistic (Myers and Tan 2002). McCoy, Galletta, and King (2007) define culture as a way of thinking exhibited by differing human groups and exhibited in the artifacts they create. Walsham (2002, p. 360) conceptualizes culture as "shared symbols, norms and values in a social collective." Culture can also be represented in visual form as artifacts. These artifacts can be physical, or they may be sets of rules, models, practices, and structured tasks (Kappos and Rivard 2008).

The increased use of IT artifacts globally has spurred the debate as to what degree culture influences usability of such artifacts. Studies on usability have acknowledged the need to study culture's impact and the importance of studying the use context (Bødker 2006; O’Brien et al. 1999). However, culture is constantly created and recreated, making it difficult to pin down (Avison and Myers 1995). If the creators of an IT artifact rely solely on generic predefined attributes of culture, this may not be 
sufficient for IS success. The key issue here is for IS researchers to understand the user. The challenge arises when the designer's culture history differs dramatically from that of the user. The metaphorical distance of the designer's culture from the users will pose problems to design. This is exemplified by studies of usability in eastern and western cultures (Diaper and Lindgaard 2008).

In striving to improve our understanding of culture, IS researchers have mostly drawn on theories and methods from the social sciences. Theories such as activity theory have been used to study the relationship between culture and IT artifacts. The artifact may embody the cultural attributes of its designers, or it may embody the cultural attributes of the intended users, or both. Another way is to focus on the meaning of an artifact within a social and cultural context (Orlikowski and Iacono 2001). Yet another way to study the relationship between culture and IT artifacts is to look at the impact of an artifact on social and culture entities. Hence, culture can influence the design of an artifact and conversely, an artifact may influence culture.

One complication, however, is that the adoption of IT artifacts often requires adoption of the creators' cultural norms, values, and practices in order to use the artifacts effectively (Lin and Silva 2005) Although the designers hope that their artifacts will make us more efficient and productive, sometimes a change in work practices can be counterproductive. Studies on the change in work practices with IS implementation have shown that users can experience "dissonance to consonance," where there are conflicts between existing work practices and the new practices introduced with IT artifacts (Vasst and Walsham 2005). This may lead to IS implementation failure.

We suggest that one possible way of trying to avoid such failure is for DSR to embrace some of the insights from qualitative and interpretive studies of culture in IS. These studies have shown that IT artifacts and systems can take on a different meaning depending upon the context. Hence it becomes important to explore the social and cultural context of IS innovations. One of the ways of doing so is to use ethnographic research, which has the potential to offer rich insights into IS phenomena (Harvey and Myers 1995). Ethnographic research differs from other research methods in the requirement for the researchers to immerse themselves to some extent in the everyday lives of the subjects. An ethnographic researcher uses interviews but relies heavily on data obtained via participant observation (Myers 2009). Of course, one potential downside is that this may extend the time taken for any DSR project, but we suggest that a judicious use of ethnographic research (perhaps along the lines of mini-ethnography) might be worthwhile. Ethnographically informed studies have been done in participatory systems design where both users and designers engage in learning activities meant to improve the understanding of the context and the user at work (Simonsen and Kensing 1997).

We suggest that a particular kind of ethnography, called critical ethnography, is particularly applicable and relevant for DSR. Just as DS researchers are oriented toward improving software or systems through the design of an IT artifact, so critical ethnographers are oriented toward improving social and cultural arrangements. Critical ethnography is participatory and seeks to do more that simply interpret the data. Critical ethnographers also have an interest in the "emancipation" of people from social, cultural, and technological constraints (Thomas 1993). A critical 
ethnographer thus engages with the subjects of the study in dialogue, attempting to reveal hidden agendas, oppressive power structures, and fallacies that inhibit the subject from participating or self-determination. Thus the critical ethnographer does not merely participate and observe, but suggests improvements (Myers 1999). In information systems, critical research has been used to aid the understanding of complex social situations involving power (Avgerou and McGrath 2007), and issues concerning the social construction of IT artifacts and their impact on organizations (Ngwenyama and Lee 1997).

\section{Culture as an Opportunity for Decision Science Research}

Stahl (2008) argues that design science researchers, like other researchers, have ethical and social responsibilities. In the design of artifacts, researchers must be aware of the potential impact of those artifacts on users. Organizations make decisions to adopt artifacts and those decisions have far reaching impacts beyond those that were intended. In the design process, researchers should be aware of these potential implications. Of course, this becomes much more important when dealing with the design of artifacts across cultures (Stahl 2008). In this paper, we seek to enhance design science research with formative evaluation, which integrates valuable attributes of the target culture to enhance the final artifact. This is consistent with the approach proposed by Pries-Heje, Baskerville, and Venable (2008). By using a formative approach to evaluation, we believe we can potentially reduce the risk of negative impact of the IT artifact by first addressing the issues of culture through critical ethnography. Design research has the potential to be empowering to the user if that user can fully participate and the culture in which he or she exists is not simply ignored or misunderstood. This has not traditionally been the approach employed in design science research (Stahl 2008) but one which we believe could be beneficial.

In Information Systems, we use design science to create IT artifacts that represent a solution to a preexisting problem or opportunity. The artifacts are broadly defined as constructs: asystem, a piece of software, hardware or a model (Hevner et al. 2004) created to fulfill the main goal of problem solving. The design science research methodology (DSRM) of Peffers et al. (2008) suggests a way to conduct design science research in information systems. It is comprised of six phases: (1) identification of problem and motivation, (2) define objectives, (3) design, (4) demonstration, (5) evaluation, and (6) communication (Peffers et al. 2008). However, we see a challenge if we try to apply DSRM in various cultural contexts. We aim to enhance DSRM by modifying the evaluation phase of the Peffers at al. model such that it is enriched with the critical ethnographic approach.

The Peffers at al. DSRM starts with the identification of research problem(s) and motivation for the research (see Figure 1). Based on evidence, reasoning, and inference, the process continues toward defining objectives of a solution to solve the research problem. This should be based on prior knowledge in the given field of research. This knowledge is then used to design and develop an artifact and to create "how to" knowledge. Following that, the artifact is used to solve the pre-described problem and is thus demonstrated in a suitable context before evaluating its 
effectiveness or efficiency. This leads to disciplinary knowledge, which is then communicated to both academia and industry. Of course, the process can, and should be, iterative in nature.

DSRM has four possible entry points to the research process. The first entry point is the traditional problem-centered initiation, which is similar to qualitative and quantitative research methodologies. The second is the objective-centered solution approach, which enables researchers to approach the research endeavor by first setting objectives that can be quantitative or qualitative with the main idea of establishing how the new artifact is expected to support solutions to achieving the stated objectives. The third entry point is design-centered, where initiation can be a result of an interesting design or development problem. The fourth entry point is where the design starts with a research client.

As we stated earlier, however, our focus is in the evaluation phase of design science. In the current model, the evaluation component acts as a reality check ensuring that the research is on the right track to deliver the needed solution, as DSRM is meant to be an iterative process where multiple periods of evaluation may be needed throughout the research process. Evaluation can inform or force a change in other phases like design or defining objectives (Peffers et al. 2008). Most importantly, we see that evaluation is a key area that can be modified to inform the artifact's effectiveness in various cultural contexts, although critical ethnographic research could also be the starting point.

To summarize our arguments so far: IT artifacts interact with social entities, such as organizations or social networks. This creates added complexity for researchers. The focus is not just on the technological artifact, but also on the people who intend to use it and its context of use. Hence, design science research needs to use theories and methods from the social sciences to better understand the behavior of social actors as they interact with systems (Hevner et al. 2004; Walls et al. 1992). We can use these theories and methods to guide the research process and influence the creation of attributes represented in the artifacts. These theories and methods have the potential to help us in the formative stage of the research process (Markus et al. 2002), and may help us to unearth aspects and perspectives previously neglected, such as the suggested cultural aspect.

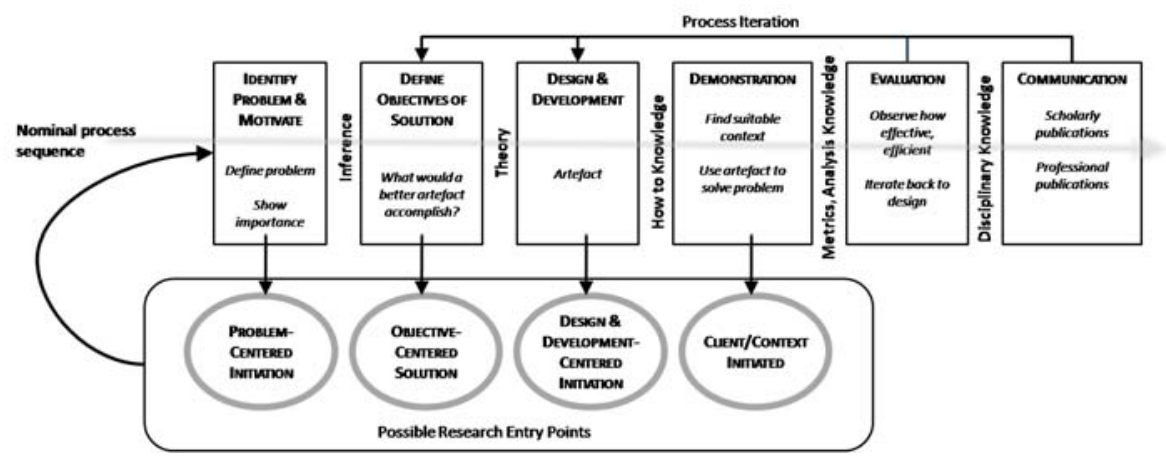

Fig. 1. Design Science Research Methodology (Adapted from Peffers et al. 2008) 


\section{Culture and Evaluation in DSRM}

Evaluation in DSR is mainly concerned with the evaluation of DS outputs, including any theory and/or artifacts developed. Although evaluation is widely recognized as an important aspect of the DSRM methodology, it is often poorly executed (PriesHeje et al. 2008). Choosing the appropriate evaluation strategy depends on the complexities of the context. In studies involving contexts where the researcher has control of the research, experimental methods may be appropriate. Studies in a real life context, however, will need to employ different methods of evaluation in order to capture the "naturalistic" processes of social life (Pries-Heje et al. 2008).

In IS, evaluation is usually considered to be the process of assessing quality based on predefined goals and objectives. Traditionally, the focus of such evaluations has been technically oriented, attempting to assess performance, reliability and usability using economic measures (Klecun and Cornford 2005). These evaluations have usually just checked the artifact against the requirements and objectives, and focused on evaluating individual users and their ability to learn and use the artifact. However, given the failure of many IT artifacts to fulfill their expected purpose and the longterm goals of the organization, there is a need for improvement in our evaluation methods. We suggest that using theories and methods from the social sciences may enhance the rigor of the evaluation and improve our understanding of the user's belief system and attitudes (Goodhue 1995).

Evaluation of IT artifacts using social theories is not as common as traditional evaluation, but can be effective in revealing dimensions that cannot be found using quantitative methods (Klecun and Cornford 2005). IT artifacts that have social applications warrant the use of these methods. The lack of IS evaluations has sometimes been linked to the cost associated with comprehensive evaluation, especially those involving theory. Even though there is some reluctance, theory driven evaluations have show to be effective in predicting success of IT artifacts (Goodhue 1995). It is important to note that evaluations are not simply used to assess an artifact's impact on the user community, but also to show its potential success.

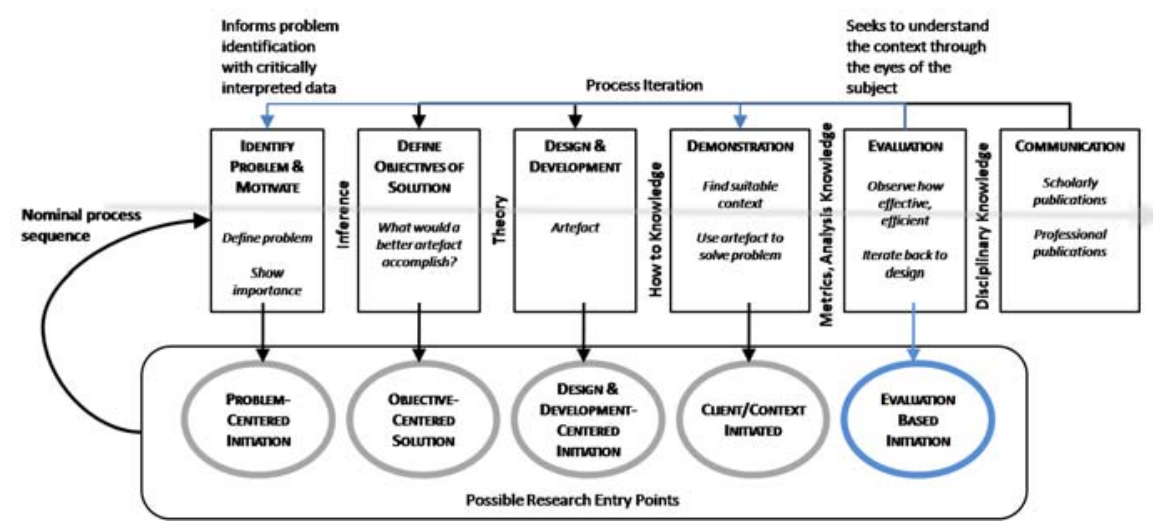

Fig. 2. Extending the DSRM with Critical Evaluation 
The use of social theory in evaluation is predominantly to understand social behavior and culture, identifying issues that are not necessarily related to technical aspects of the systems, but may affect its use and acceptance. For example, social theory shows how users change their evaluations "post adoption" and how their evaluation continues to change over time (Kim and Malhotra 2005). Of course, as we stated earlier, culture is not static and thus users' views on IS artifacts can be expected to change over time. Simply looking at the objectives and the solution itself cannot reveal these dimensions. Research using social theories has also shown that users use existing knowledge to form their opinion of a product or service (referred to as an anchor) and develop new views as they acquire new knowledge (referred to as an adjustment) (Kim and Malhotra 2005).

We propose extending DSRM such that it integrates elements of critical ethnography to the evaluation of DSR outputs to identify any mismatch between the use context and the design context. We therefore suggest that the process of DSRM should have an entry point at evaluation. We call this evaluation based initiation. The extended DSRM is shown in Figure 2. Traditionally, in post-design evaluations the focus is on a the individual user's ability use the systems effectively, whereas here in the formative context we focus of the larger social group, examining real-life context and interactions (Sayago and Blat 2009). We recognize the design context and understand that that context may be vastly different from the use context resulting in inappropriate artifacts. Recognizing the danger of such a potential mismatch, we see it as logical to use formative evaluation to understand the context of use prior to commencing with problem identification. With the critical ethnographic approach, the evaluation seeks to understand the context through the eyes of the subjects. It not only interprets the users' point of view, but also has as an objective to question and reveal hidden power structures and agendas that inhibit the effectiveness of the potential artifact. This process potentially sensitizes the researcher to the cultural contexts, giving a richer perspective. This process in turn informs problem identification, giving a clearer picture of what is required. The ultimate aim, of course, is to improve the DSR process such that the resulting artifacts contribute in some way to improving the human condition.

\section{Demonstration of the Extended DSRM}

We demonstrate the extended DSRM by reviewing a study that enabled us to coin the idea of formative critical ethnography driven evaluation. The presence study, described below, was done within the DiVia (http://www.divia.fi) research project and LTT Research, Inc., a commercial research firm owned by the Helsinki School of Economics. The study was led by one of the authors of this paper and it has included 15 researchers from four continents. So far, the study has involved some 450 participants in Auckland, Helsinki, Hong Kong, and Las Vegas. The research project is still ongoing with its first iteration concluded in 2007. The study's preliminary results were reported earlier (Peffers et al. 2006; Tuunanen et al. 2006). Here, we first summarize the primary research round using the DSRM (Peffers et al. 2008), and then we focus on the on-going second iteration. 


\subsection{Problem Identification and Motivation}

Presence technology allows mobile device users to share information about their current availability and status in terms of their own concepts or those of a presencebased application with subscribers to that information. For example, a basic presence service could allow users to publish their information and share it with others in order to make mobile communication and services more sensitive and personal. This information may include the availability of the subscriber, the preferred means of communication, the subscriber's whereabouts, as well as visual content for self expression of one's emotion, in order to guide other users' communication decisions while controlling their own information (Nokia 2005). Examples of presence information might include "sleeping," "in a meeting-leave voice mail," "bored-call me," "at leisure and looking for fun."

First, we aimed to identify the research problem. As presence technology was new to us and to the markets, we planned to use industry experts to provide us with a focused application scope within the domain. Therefore, we recruited 13 marketing professionals from firms participating in DiVia to help us with this and planned a group support system (GSS) session to define the project scope. The GSS session was done in May 2004. The results included recommendations for three application problems for presence: (1) presence-enabled mobile travel services for while you are en-route; (2) presence-enabled mobile service while you are out and about in the city; and (3) presence-enabled mobile service for special interest group member/community. We added one extra stimulus to the final list: a presence enabled mobile service "for you." We originally set as our research problem the identification of what consumers might want to have from presence enabled mobile services.

\subsection{Objective: Presence Enabled Mobile Marketing Applications}

We were faced with a situation where we would need to discover requirements for a service that does not exist using a technology not familiar to end-users. This puts forth several objectives for a solution. First, the number of users can be very large and they can be widely dispersed geographically. Second, the lack of control and poor incentives may result in volatile data collection. Finally, the end-users have a low level of integration to the service or it can be of a secondary nature. These characteristics are highlighted by the fact that many end-users do not even know how to express their needs (Walz et al. 1993; Watson and Frolick 1993). In this study, we applied a specially developed method for resolving these issues: the wide audience requirements engineering (WARE) method (Tuunanen et al. 2004).

\subsection{Design: Using Ware to Discover Requirements}

The WARE method starts with project definition and selection of participants. The second phase is data gathering. Earlier studies have recommended interviewing approximately 30 people per research location (Griffin and Hauser 1993) as this would be a large enough sample to suffice for discovering 90 percent or more of the potential ideas about a concept from a population. Our previous studies, which have used a similar data gathering method, have concurred with this view (Peffers et al. 
2003; Peffers and Tuunanen 2005). The literature further recommends that the sample be representative of the end-user segments.

We suggest that "lead users" should be included in the sample. The sample consisted of lead users because the research literature suggests lead users can be used to forecast the needs of the majority of users of a technology (Rogers 1995; von Hippel 1986; von Hippel and Katz 2002). Therefore, we used the "snowball" method to recruit participants, a set of six questions to screen potential participants as lead users and a second set of questions to learn what kind of knowledge the participant had on the domain area of the study. This recruitment process resulted in a panel of 80 participants: 28 from Helsinki, 27 from Hong Kong, and 25 from Las Vegas.

In all locations, we interviewed each of the participants individually and in person. During the interviews, the interviewers made digital audio recordings and took notes with an electronic spreadsheet application or using pen and paper. Before conducting the interviews, the participant was shown a flash demonstration of presence technology. After the demonstration, the participants were told to try to think outside of the offered presence technology and think of something else that could use the technology. The interviews were done with the laddering interviewing technique (Browne and Ramesh 2002; Browne and Rogich 2001; Peffers et al. 2003; Peffers and Tuunanen 2005). The laddering data consisted of 597 chains of individual requirements and 3,113 specific requirements. The data was aggregated to produce a meaningful, and smaller, set of rich, unified, and aggregated models, which makes it easier for managers and designers to comprehend the data. Finally, the aggregated data was used for creating network maps by transforming the clustered chains in each theme into a network map. Further details are available in Peffers et al. (2006) and Tuunanen et al. (2006).

Based on the results of the data collection phase, we provided an analysis of the situation and described the potential needs of end users (i.e. user requirements). This was initially done in a business report delivered to project member firms and institutions. The report gave recommendations for focusing resources on developing features and develops a roadmap for presence services.

\subsection{Demonstration: Rapid Development of Presence Services}

For the demonstration phase and for building the artifact (a presence-enabled mobile marketing application), we applied the concepts of method engineering (ME). Method engineering provides means to specify, make explicit, codify, and communicate method knowledge as well as technical tools to enact such processes effectively. Tuunanen and Rossi (2004) have suggested that in order to model IS requirements we need a set of concepts during ME that can capture the content and form of any development method into a meta-model. Brinkkemper (1990) has said that in its simplest form, a meta-model is a conceptual model of a development method. Therefore, meta-modeling can be defined as a process, which takes place on one level of abstraction and logic higher than the primary modeling process (van Gigch 1991).

We used a domain-specific modeling method initially within MetaEdit+ (Kelly et al. 1996) and later by developing a eclipse-based meta modeling environment to rapidly produce prototypes from the requirements. There are several implementations available (e.g., Tuunanen and Rossi 2003, 2004) and we are currently working on the eclipse-based environment (Przybilski 2006) that generates running prototypes for a 
mobile-specific platform, like the MIDP Java or Symbian platform (Rossi and Tuunanen 2004).

\subsection{Evaluation: Realization of the Importance of Culture}

The evaluation of the artifacts was initially considered to be done with distributed conjoint analysis (Laaksonen et al. 2004). We saw that this would be necessary to ensure (1) that the potential end-users of developed services would fully understand the choices they are making about the service features, and (2) that we as researchers could better understand how we could model and discover the latent needs for such services. We ended up not doing this due the realization of the importance of culture in requirements, especially if one desires to develop a global mobile service.

In the design phase of the study and while gathering requirements data we began to understand the difficulties of global service development. Our preliminary findings on the differences of culturally based requirements (Tuunanen et al. 2006) showed that our three different data gathering locations-Helsinki, Hong Kong, and Las Vegashad distinctly different needs for presence type mobile services. Furthermore, we concluded that even though we were able to aggregate the results of requirements discovery to several service concepts, which included features based on all three locations, we began to question if it would actually make sense to develop the requirements and later the system in this way. We would, in fact, be doing the same as mobile firms have done so far: that is, trying to stereotype the global consumer and put all the bells and whistles in the same "box." We thought that this would very likely derail us from understanding the needs of consumers of presence services in each of the three locations.

This new understanding had two major impacts on our study. First, we realized that we would have to redesign our approach of requirements analysis to include the cultural aspects of requirements. Therefore, our evaluation phase drove us to return to the design phase of the study and develop a new requirements analysis method, which would take account of cultural reasoning of requirements for systems. This led us to change the research problem to a more theory-driven approach to applying DSRM. This linkage is illustrated in the Figure 2 as a loop back to problem setting and potentially to the demonstration phase.

Second, we realized that culturally oriented DS research might be a fruitful new area where research can commence from the evaluation of the results of a research project. Peffers et al. (2008) have proposed that such an area of study might be possible. Critical ethnography in particular might be able to provide us with a better understanding of complex social situations involving culture and complex mobile services. This, in turn, might lead to new research ventures as suggested by our extended DSRM methodology.

\section{Conclusions}

Culture presents many challenges for IS design science researchers seeking to design IT artifacts for a global society. The need for theory informed evaluation to improve the final artifact is evident given the different social phenomena that influence its use, adoption, and impact. When designing for multiple cultures, we have to look beyond the surface and evaluate deeper meanings. 
This paper has suggested that by applying critical ethnography to the evaluation phase of the DSRM we can extend design science research methodology (Peffers et al. 2008). This enhancement is driven by the need for greater attention to cultural issues in our global society, particularly when the artifact is being designed for different cultural contexts. The paper thus integrates critical ethnography into the evaluation phase of the DSRM, which informs the other phases of the methodology. The need for the proposed extended DSR methodology is demonstrated through a case study in global mobile service development, which drove the development of this paper.

The limitations of our paper are as follows. First, we recognize that we have only briefly summarized the vast amount of literature covering design science research, ethnography, and social theory. Our discussion of culture and critical ethnography is limited. We are first to acknowledge that our paper stops far short in its explanation of how, in a detailed practical way, critical ethnography might be applied to evaluation in DS research.

However, we believe we have sufficiently shown the need to enhance the design process when it comes to culture, and we have suggested one way in which this might be achieved. Further research involving both design science researchers and ethnographers in information systems is needed to develop a framework or model for a more precise evaluation process. It is imperative that IS designers and researchers continue to search for the best available approaches to design, so we can create more usable artifacts to enrich the users' experience.

\section{References}

Avgerou, C., McGrath, K.: Power, Rationality, and the Art of Living Through Socio-Technical Change. MIS Quarterly 31(2), 295-315 (2007)

Avison, D.E., Myers, M.D.: Information Systems and Anthropology: An Anthropological Perspective on IT and Organizational Culture. Information Technology \& People 8(3), 43$56(1995)$

Bødker, S.: When Second Wave HCI Meets Third Wave Challenges. In: Proceedings of the 4th Nordic Conference on Human-Computer Interaction, Changing Roles, Oslo, Norway (2006)

Brinkkemper, S.: Formalisation of Information Systems Modelling. Computer Science Department, University of Nijmegen (1990) (unpublished paper)

Browne, G.J., Ramesh, V.: Improving Information Requirements Determination: A Cognitive Perspective. Information \& Management 39(8), 625-645 (2002)

Browne, G.J., Rogich, M.B.: An Empirical Investigation of User Requirements Elicitation: Comparing the Effectiveness of Prompting Techniques. Journal of Management Information Systems 17(4), 223-249 (2001)

Diaper, D., Lindgaard, G.: West Meets East: Adapting Activity Theory for HCI \& CSCW Applications? Interacting with Computers 20(2), 240-246 (2008)

Goodhue, D.L.: Understanding User Evaluations of Information Systems. Management Science 41(12), 1827-1844 (1995)

Griffin, A., Hauser, J.R.: The Voice of the Customer. Marketing Science 12(1), 1-27 (1993)

Harvey, L., Myers, M.D.: Scholarship and Practice: The Contribution of Ethnographic Research Methods to Bridging the Gap. Information Technology \& People 8(3), 13-27 (1995) 
Hevner, A.R., March, S.T., Park, J., Ram, S.: Design Science in Information Systems Research. MIS Quarterly 28(1), 75-105 (2004)

Hofstede, G.: Cultural Consequences: International Differences in Work Related Values. Sage Publications, Beverly Hills (1980)

Hofstede, G.: Cultures and Organizations: Software of the Mind. McGraw-Hill, New York (1991)

Kappos, A., Rivard, S.: A Three-Perspective Model of Culture, Information Systems, and Their Development and Use. MIS Quarterly 32(3), 601-634 (2008)

Kelly, S., Lyytinen, K., Rossi, M.: MetaEdit+: A Fully Configurable Multi-User and MultiTool CASE and CAME Environment. In: Constantopoulos, P., Vassiliou, Y., Mylopoulos, J. (eds.) CAiSE 1996. LNCS, vol. 1080, pp. 1-21. Springer, Heidelberg (1996)

Kim, S.S., Malhotra, N.K.: A Longitudinal Model of Continued IS Use: An Integrative View of Four Mechanisms Underlying Postadoption Phenomena. Management Science 51(5), 741755 (2005)

Klecun, E., Cornford, T.: A Critical Approach to Evaluation. European Journal of Information Systems (14), 229-243 (2005)

Kumar, K., Van Dissel, H.G., Bielli, P.: The Merchant of Prato-Revisited: Toward a Third Rationality of Information Systems. MIS Quarterly 22(2), 199-225 (1998)

Laaksonen, A., Tuunanen, T., Rossi, M.: Requirements Validation for Consumer Software by Conjoint Analysis. In: Proceedings of the 13th International Conference on Information Systems Development, Vilnius, Lithuania, August 26-28. Kluwer/ Plenum Press, Boston (2004)

Lin, A., Silva, L.: The Social and Political Construction of Technological Frames. European Journal of Information Systems 14(1), 49-59 (2005)

Markus, M.L., Majchrzak, A., Gasser, L.: A Design Theory for Systems That Support Emergent Knowledge Processes. MIS Quarterly 26(3), 179-212 (2002)

McCoy, S., Galletta, D.F., King, W.R.: Applying TAM Across Cultures: The Need for Caution. European Journal of Information Systems 16(1), 81-90 (2007)

Myers, M.D.: Investigating Information Systems with Ethnographic Research. Communications of the AIS 2(23), 1-20 (1999)

Myers, M.D.: Qualitative Research in Business \& Management. Sage Publications, London (2009)

Myers, M.D., Tan, F.: Beyond Models of National Culture in Information Systems Research. Journal of Global Information Management 10(1), 24-32 (2002)

Ngwenyama, O.K., Lee, A.S.: Communication Richness in Electronic Mail: Critical Social Theory and the Contextuality of Meaning. MIS Quarterly 21(2), 145-166 (1997)

Nokia, Staying in Touch with Presence, white paper, Nokia, Inc. (2005)

O'Brien, J., Rodden, T., Rouncefield, M., Hughes, J.: At Home with the Technology. ACM Transactions on Computer-Human Interaction 6(3), 282-308 (1999)

Orlikowski, W.J., Iacono, C.S.: Research Commentary: Desperately Seeking the 'IT' in IT Research-A Call to Theorizing the IT Artifact. Information Systems Research 12(2), 121-134 (2001)

Peffers, K., Gengler, C., Tuunanen, T.: Extending Critical Success Factors Methodology to Facilitate Broadly Participative Information Systems Planning. Journal of Management Information Systems 20(1), 51-85 (2003)

Peffers, K., Tuunanen, T.: Planning for IS Applications: A Practical, Information Theoretical Method and Case Study in Mobile Financial Services. Information \& Management 42(3), 483-501 (2005) 
Peffers, K., Tuunanen, T., Hui, W., Gengler, C., Rossi, M., Virtanen, V., Bragge, J.: The Design Science Research Process: A Model for Producing and Presenting Information Systems Research. In: Proceedings of the First International Conference on Design Science Research, Claremont, CA, pp. 83-106 (2006)

Peffers, K., Tuunanen, T., Rothenberger, M.A., Chatterjee, S.: A Design Science Research Methodology for Information Systems Research. Journal of Management Information Systems 24(3), 45-77 (2008)

Pries-Heje, J., Baskerville, R., Venable, J.: Strategies for Design Science Research Evaluation. In: Golden, W., Acton, T., Conboy, K., van der Heijden, H., Tuunainen, V. (eds.) Proceedings of the 16th European Conference on Information Systems, Galway, Ireland, pp. 255$266(2008)$

Przybilski, M.: Requirements Elicitation in International Research Projects. In: Proceedings of the 12th Americas Conference on Information Systems, Acapulco, Mexico, August 4-6 (2006)

Rogers, R.M.: Diffusion of Innovations. The Free Press, New York (1995)

Rossi, M., Tuunanen, T.: A Method and Tool for Wide Audience Requirements Elicitation and Rapid Prototyping for Mobile Systems. In: Wang, S., Tanaka, K., Zhou, S., Ling, T.-W., Guan, J., Yang, D.-q., Grandi, F., Mangina, E.E., Song, I.-Y., Mayr, H.C. (eds.) ER Workshops 2004. LNCS, vol. 3289, pp. 629-640. Springer, Heidelberg (2004)

Sayago, S., Blat, J.: Telling the Story of Plder People e-Mailing: An Ethnographical Study. International Journal of Human-Computer Studies 10(4), 1-33 (2009)

Simonsen, J., Kensing, F.: Using Ethnography in Contextual Design. Communications of the ACM 40(7), 82-88 (1997)

Stahl, B.: Design as Reification, Commodification, and Ideology: A Critical View of IS Design Science. In: Golden, W., Acton, T., Conboy, K., van der Heijden, H., Tuunainen, V. (eds.) Proceedings of the 16th European Conference on Information Systems, Galway, Ireland, pp. 207-218 (2008)

Thimbleby, H., Cairns, P., Jones, M.: Usability Analysis with Markov Models. ACM Transactions on Computer-Human Interaction 8(2), 99-132 (2001)

Thomas, J.: Doing Critical Ethnography. Sage Publications, Newbury Park (1993)

Tuunanen, T., Peffers, K., Gengler, C.: Wide Audience Requirements Engineering (WARE): A Practical Method and Case Study, electronic working paper series, Helsinki School of Economics (2004)

Tuunanen, T., Peffers, K., Gengler, C., Hui, W., Virtanen, V.: Developing Feature Sets for Geographically Diverse External End Users: A Call for Value-Based Preference Modeling. Journal of Information Technology Theory \& Application 8(2), 41-55 (2006)

Tuunanen, T., Rossi, M.: An Advanced Requirements Elicitation Method and Tool. In: Proceedings of the WITS 2003, Seattle, Washington (2003)

Tuunanen, T., Rossi, M.: Engineering a Method for Wide Audience Requirements Elicitatation and Integrating It to Software Development. In: Proceedings of the 37th Hawaii International Conference on System Sciences. IEEE Press, Los Alamitos (2004)

van Gigch, J.: System Design Modeling and Metamodeling. Plenum Press, New York (1991)

Vasst, E., Walsham, G.: Representations and Actions: The Transformation of Work Practices with IT Use. Information and Organization (15), 65-89 (2005)

von Hippel, E.: Lead Users: A Source of Novel Product Concepts. Management Science 32(7), 791-805 (1986)

von Hippel, E., Katz, R.: Shifting Innovation to Users Via Toolkits. Management Science 48(7), 821-833 (2002)

Walls, J.G., Widmeyer, G.R., El Sawy, O.A.: Building an Information System Design Theory for Vigilant EIS. Information Systems Research 3(1), 36-59 (1992) 
Walsham, G.: Cross-Cultural Software Production and Use: A Structurational Analysis. MIS Quarterly 26(4), 359-380 (2002)

Walz, D., Elam, J., Curtis, B.: Inside a Software Design Team: Knowledge Acquisition, Sharing and Integration. Communications of the ACM 36(10), 62-77 (1993)

Watson, H.J., Frolick, M.N.: Determining Information Requirements for an EIS. MIS Quarterly 17(3), 255-269 (1993)

\section{About the Authors}

Carl Lawrence is a Ph.D. student at the University of Auckland in the field of information systems. He has over 12 years experience in corporate IT management, project management and systems analysis. His research interests include cross-cultural innovation, information systems in developing countries, activity theory and design science. Mr. Lawrence can be reached by e-mail at claw054@aucklanduni.ac.nz.

Tuure Tuunanen is a senior lecturer in the Department of Information Systems and Operations Management at the University of Auckland. He is also Visiting Professor of Work Informatics at the University of Turku, an associate professor (adjunct) of MIS at the University of Nevada, Las Vegas, and Center of Service Leadership Global Faculty Member at Arizona State University. He holds a D.Sc. (Economics) from the Helsinki School of Economics. His current research interests lie in the areas of IS development methods and processes, requirements engineering, risk management, and convergence of IS and marketing disciplines, specifically in design of interactive consumer services and products. His research has been published in Information \& Management, Journal of the Association for Information Systems, Journal of Database Management, Journal of Information Technology Theory and Application, Journal of Management Information Systems, and Technology Analysis and Strategic Management. Dr. Tuunanen is a member of Association of Computing Machinery, Association for Information Systems, and Institute of Electrical and Electronics Engineers. Dr. Tuunanen is a coeditor-in-chief of Journal of Information Technology Theory and Application. He can be reached by e-mail at tuure@tuunanen.fi.

Michael D. Myers is Professor of Information Systems and Head of the Department of Information Systems and Operations Management at the University of Auckland Business School, New Zealand. His research articles have been published in many journals and books. He won the Paper of the Year award (with Heinz Klein) for the most outstanding paper published in MIS Quarterly in 1999. This paper has been cited over 1,500 times and is third most cited paper to appear in MIS Quarterly. He also won the Best Paper Award (with Lynda Harvey) for the best paper published in Information Technology \& People in 1997. He currently serves as a senior editor of Information Systems Research and as editor of the ISWorld Section on Qualitative Research. He previously served as a senior editor of MIS Quarterly from 2001-2005 and as an associate editor of Information Systems Journal from 19952000. He also served as President of the Association for Information Systems (AIS) in 2006-2007 and as Chair of the International Federation of Information Processing (IFIP) Working Group 8.2 from 2006-2008. Dr. Myers can be reached at m.myers@auckland.ac.nz. 